Low-income Families and Coping through Brands: Inclusion or Stigma?

Kathy Hamilton

University of Strathclyde, Glasgow

\author{
Department of Marketing \\ University of Strathclyde \\ Stenhouse Building \\ 173 Cathedral Street \\ Glasgow \\ Scotland \\ G4 0RQ
}

kathy.hamilton@strath.ac.uk

Tel: +44 (0)1415483240 


\title{
Low-income Families and Coping through Brands: Inclusion or Stigma?
}

\begin{abstract}
This paper highlights the paradoxical coping strategies employed by low-income families. Based on in-depth interviews with 30 families in the UK, it is demonstrated that individuals initiate strategies to avoid the social effects of stigmatization and alleviate threats to social identity. In particular, families engage in conspicuous consumption, with emphasis on ensuring children have access to the 'right' brands. This can be interpreted in two opposing ways. Low-income consumers, in particular single mothers, may be understood as coping within the challenging context of consumer culture to improve the standard of living for their families. However, drawing on underclass discourse surrounding 'chav' culture and single mothers, it is demonstrated that the coping strategies employed to achieve approval in fact fuel further stigmatization and instead of creating inclusion have the opposite outcome of exclusion and marginalization.
\end{abstract}

Keywords: brands, consumption, coping, poverty, qualitative, stigma. 


\section{Low-income Families and Coping through Brands: Inclusion or Stigma?}

It is widely acknowledged that we live within a consumer culture (Featherstone, 1990) where consumers are expected to respond to marketplace temptations. Shopping and consumption provide consumers with resources for the construction and maintenance of identity, which in turn offers consumer normalcy (Baker, 2006). Within this context, those who are constrained in consumption opportunities face exclusion and stigmatization (Power, 2005). This paper considers low-income consumers who encounter relative poverty due to their inability to obtain the goods and services needed for an 'adequate' and 'socially acceptable' standard of living (Darley \& Johnson, 1985, p. 206). Poverty is more than a material condition, it is also a psychological and social state as 'the poor of a consumer society are people with no access to a normal life, let alone to a happy one' (Bauman, 2005, p. 38). Unlike their more affluent counterparts, low-income consumers do not have the luxury of continually (re)constructing consumer identities. The limited research on consumer exclusion has considered the coping strategies employed to avoid stigmatization and social disapproval. This research suggests that individuals on low incomes can improve their situations and develop self esteem through initiating various creative strategies to respond to their family's demands (Hamilton \& Catterall, 2006; Hamilton, 2009). However, analysis will reveal that coping strategies which seem functional and effective at the micro level may have unanticipated outcomes if considered within the wider societal context. Drawing on already-published material on chav discourse (e.g. Hayward \& Yar, 2006; Tyler, 2008; Nayak, 2006), it will be suggested that the coping strategies employed by low-income families to disguise poverty and portray a socially acceptable image can actually create further stigmatization. In particular, the following two research questions will be addressed. Firstly, in what ways do those living on a low income use consumption to cope? Secondly, how can these coping strategies be 
interpreted with reference to published material on consumer exclusion? By focusing on the lived experience of poverty as well as social discourse, this approach combines individual and macro levels of analysis aiming to provide a more complete picture of the realities of life on a low income.

The paper will begin with an overview of low-income consumers with emphasis on coping with poverty. Next, the qualitative methodological approach will be described. The findings will begin with three vignettes illustrating the participants' lived experience of poverty. The paradoxes of consumption in poverty will then be discussed in relation to both stigma avoidance strategies and feelings of empowerment. Firstly, it will be suggested that coping strategies can create feelings of empowerment and self-worth. Secondly, it will be demonstrated that the coping strategies employed to achieve approval in fact fuel further stigmatization and instead of creating inclusion may have the opposite outcome of exclusion and marginalization.

\section{LOW-INCOME CONSUMERS}

The latest Joseph Rowntree Foundation (2009) report on poverty and social exclusion indicated that in 2007/8, 13.4 million people in the UK were living in low-income households, representing around one-fifth of the population. This refers to a household income that is less than 60 percent of the median UK household income in that year. However, despite such statistics, poverty remains outside the norms of consumer culture. The poor as consumers are 'inadequate,' 'unwanted,' 'abnormal,' 'blemished, defective, faulty and deficient,' 'flawed consumers' and 'non-consumers' (Bauman, 2005, p. 38, 112-113). 
Hill \& Stephens' (1997) model of impoverished consumer behaviour suggested that poor consumers face exchange restrictions that limit their ability to acquire needed and desired goods and services. Restrictions arise from both sides of the exchange relationship i.e. restrictions stemming from the limited purchasing power and restricted income sources of low-income consumers, as well as restrictions imposed by suppliers, including price discrimination in the form of higher prices (Caplovitz, 1967), low quality goods (Williams \& Windebank, 2001) and limited choice (Curtis, 2000). The consequences of these restrictions are typically negative and include feelings of lost control and separation from the consumer culture (Hill \& Stephens, 1997). Poor consumers respond with emotional and behavioural coping strategies. In line with the focus of this paper, the following section provides further detail on coping strategies employed.

\section{COPING WITH POVERTY}

Coping can be defined as, 'constantly changing cognitive and behavioral efforts to manage specific external and/or internal demands that are appraised as taxing or exceeding the resources of the person' (Lazarus \& Folkman, 1984, p. 141). Coping has two major functions, firstly, regulating stressful emotional situations and secondly, altering the troubled personenvironment relation causing the distress. These functions are often referred to as emotionfocused coping and problem-focused coping respectively (Lazarus \& Folkman, 1984; Folkman et al., 1986). Emotion-focused forms of coping are aimed at reducing emotional distress and are common in encounters appraised as unchangeable or uncontrollable (Folkman et al., 1986; Carver et al. 1989). Problem-focused forms of coping include direct efforts to generate possible solutions and are normally used in encounters that are appraised 
as changeable or controllable (Lazarus \& Folkman, 1984; Folkman et al., 1986; Carver et al. 1989). A dated study on how adults cope with the stressful events of daily life indicated that both problem-focused and emotion-focused functions were utilised in virtually every stressful encounter (Lazarus \& Folkman, 1984).

For low-income consumers, emotional coping strategies include distancing or fantasizing about a better future (Hill \& Stephens, 1997). Hill \& Stamey (1990) found that distancing is particularly relevant to the homeless to distinguish themselves from more dependent peers and to demonstrate how they live independently by their own resources rather than under the control of welfare institutions. Fantasies about future home lives are used to reduce the stress associated with current circumstances (Hill, 1991) and replace the threat with a more acceptable form of reality (Breakwell, 1986). Hill (1991) identified religion as being important for low-income consumers because poverty often reduces attachment to typical consumer goods. Memories, relationships and religious beliefs, as well as tangible items that symbolize these intangibles, become more important.

In relation to problem-focused strategies, Kempson et al. (1994) examined the circumstances and experiences of seventy-four families with children, living on very low incomes and identified maximizing income (e.g. working overtime or taking on more than one job), managing the family budget (e.g. cut back on individual luxury items), obtaining financial help from others and making use of consumer credit as key behavioural coping responses. Miller (1998) identified strategies women used for thrift shopping in supermarkets, for example, the search for savers in the form of the supermarkets' own label goods and taking a basket instead of a trolley in order to purchase less. Illicit income coming from informal work such as babysitting, or from illegal activities such as prostitution or selling drugs may also be 
employed as a coping strategy (Hill \& Stephens, 1997). While there has been some research on the coping strategies employed by low-income families, the consequences of these coping strategies have not been addressed. A focus on coping strategies alone may obscure important insights that may be gained from examining the impact of these strategies on the individual and the family.

\section{METHODOLOGY}

Isaken \& Roper (2008) suggested that qualitative research is needed to gain a deep comprehension of the emotional impacts of consumption constraints. Examples of research adopting this approach include Lewis' (1965) anthropological study of poverty, MacDonald \& Marsh's (2005) ethnographic study exploring the experiences of excluded youth in Britain's poor neighbourhoods, Blackman's (1997) analysis of unemployed and homeless young people and Williamson's (1997) research involving Status Zer0 young people.

This study involved a total of 30 families including 25 single parent families and five twoparent families. Consistent with the feminization of poverty, 24 of the single parents were female (Hill \& Stephens, 1997). The sample was selected purposefully (Patton, 2002) from urban areas of Northern Ireland. All but three of the adults were unemployed, one was employed full-time and two were working part-time, all in low-paid jobs. The income level of the families averaged at $£ 150$ per week, which is well below the results of the Poverty and Social Exclusion Survey of Britain which indicated that the weekly income after tax needed to escape overall poverty averaged $£ 239$ for all households (Gordon et al., 2000). Full sample details are provided in table 1. 
TABLE 1 here

\section{Data Collection}

In-depth interviews formed the basis of data collection. Given that poverty can affect the whole family unit, a family approach was adopted in that all households included at least one child under the age of 18. In 21 families, only the parents were interviewed involving individual interviews in single parent families and couple interviews in two-parent families. These were families where the children were under 11 years old (i.e. secondary school age) and deemed too young to participate. In 9 families it was possible to arrange an interview with parents and children together (aged 11 to 18). The interviewing of multiple family members permits a deeper understanding of the family dynamics in terms of each person's role and influence in consumption decisions. In some family interviews, the presence of teenage children appeared to inhibit discussion of the children's understanding of the family's finances. To illustrate, in one interview involving a mother (Janet) and her 16 year-old daughter (Pamela), it was only when Pamela left the room that Janet commented on Pamela's reluctance to prioritise in managing the family budget. However, there was always an opportunity to talk to the parent(s) alone and consequently, there are no significant differences in findings between different interview formats.

Interviews were conducted in respondents' homes. As researchers are 'outsiders' to family life, this approach offers the benefit of obtaining glimpses of the 'inside' (Franklin, 1996, p. 253). Children seemed to appreciate this setting, with some of the younger participants making use of various 'props,' for example, the display of possessions. Interview topics 
included everyday life (evaluation of circumstances relative to other families and friends, feelings about shortage of money and its effect on children), budgetary strategies (management of the household budget, acquisition sites for goods and services), hopes for the future, family background information and financial circumstances (sources of income, attitudes to credit). The emphasis was on obtaining the subjective perspectives of the respondents at the level of lived experience. Interviews lasted approximately one hour and with permission were audio-recorded and later transcribed. Pseudonyms are used to protect the identity of informants and ethical approval was obtained.

\section{Data Analysis}

Interview transcripts and notes taken by the researcher formed the foundation of the analysis. Analysis began while interviewing was still under way as the overlapping of data collection and analysis is said to improve both the quality of the data collected and the quality of the analysis (Patton, 2002). Hermeneutics was used to interpret the data. This is an iterative process, "in which a "part" of the qualitative data (or text) is interpreted and reinterpreted in relation to the developing sense of the "whole" (Thompson et al. 1994, p. 433). These iterations allow a holistic understanding to develop over time, as initial understandings are modified as new information emerges. This part-to-whole process involved two stages. Firstly, each individual interview was interpreted. Secondly, separate interviews were related to each other and common patterns identified. In this paper, the data interpretation is advanced by considering the lived experience of low-income consumers within the context of chav and single mother discourse, drawing on already-published material (e.g. Hayward \& Yar, 2006; Tyler, 2008; Nayak, 2006). 


\section{FINDINGS}

To begin the findings, an idiographic overview of three of the families will be presented to contextualize the study and provide an insight into respondents' daily lives. This will be followed by a discussion of the consumption paradoxes associated with coping with poverty.

Sarah is 46 years old with 6 children (aged 25, 20, 16, 15, 13 and 11) and 2 grandchildren. She has not worked in paid employment since her first child was born and believes her 'working days are over.' Sarah lives in a neighbourhood where there are high crime levels: 'with the joyriding and all, they use that road out there like it's a bloody racetrack, you'd be scared.... When I moved in here, I'm very nervy, I wasn't used to it, cars flying up and down, joyriding, I used to run up the stairs and hide.'

Her home has also been petrol bombed. Her 16 year old son is currently in a young offender's institution which Sarah attributes to his involvement with a 'bad crowd.' Entertainment activities for the family are limited. When asked about holidays, Sarah replies that they are planning a day trip around visiting her sister's grave who committed suicide three weeks prior to the interview: 'it takes them away from here you know what I mean, we'll bring a couple of bags of crisps and things.' Sarah feels pressurized into buying brand name clothing for her children, 'because if I was to buy them cheap stuff they won't wear them, they're only going to be laughed at in the street, you go for the kids that way to so as they're not going to be bullied.' This conspicuous consumption also extends to the home: 'Around here they're all trying to compete with one another, whose house is the nicest.' Sarah used the $£ 3000$ insurance money she received after the petrol bomb to buy a television and hi-fi system. As regards her personal consumption, cigarettes and beer are the main source of expenditure 
alongside occasional jewellery purchases, particularly gold rings, through the informal economy:

'I would buy them, round the doors, I always say come to me on Mondays if you're selling anything and there's a guy, you only get him every couple of weeks in a van and he's selling cheap gear. If you knew when he was coming you would try and save.'

Susan is 23 years old with 2 daughters aged 5 and 2 . She is a single parent who works parttime (15 hours per week) as a waitress. She has recently separated from her children's father who is still in regular contact. Susan is one of the few adults in the study who likes food shopping: 'I like being able to spend money.' While many adults claim to be smart food shoppers who strive to minimize expenditure, Susan prefers brand name food products and admits, 'if I see something that I like I just buy it.' This attitude also extends to consumption in other areas, particularly clothing. She cites several high street stores that she frequently visits and claims 'I do go shopping for myself, I will spend money, I'll not go cheap on myself.' There is also some suggestion that her children have been socialized into expensive consumption patterns. Despite her daughter being only 5 years old, she has high expectations as regards apparel choice: 'she knows Nike, she knows Nike cause her Daddy wears Nike and she says "oh I want a pair the same as my daddy." Susan gives in to these demands admitting, 'I'm a bit of an impulse buyer, if I see something and I like it I don't care how expensive it is, I would buy it, even if it left me really short I would buy it.' Susan has the advantage of a strong family circle that provides emotional, practical and financial support.

Denise (43) and Barry (40) have two teenage sons, aged 15 and 17. Although both are unemployed, they believe that remaining on welfare benefits is the best financial option and are not making any effort to seek employment. A reoccurring topic of conversation 
throughout the interview is the struggle involved in meeting their sons' clothing demands. Denise claims that 'the price of clothes would drive you to distraction' citing $£ 49$ for branded designer or sports T-shirts and $£ 130$ for a pair of trainers as examples of her sons' many high expectations. Barry agrees that 'it's ridiculous, they won't wear cheap stuff. They just refuse point blank. And then I'd say you're not getting that and they won't go out.' Denise and Barry attribute this situation to peer pressure in that 'they have to look as good as everybody else' and 'nobody wants their kids to be laughed at on the streets.' Although they do not agree with using their limited budget in this way, they feel there is little option 'you have to let them have it, you don't want them out stealing.' This often results in the family turning to credit, particularly at Christmas which Barry describes as the 'most stressful time of the year.' Both Barry and Denise are very aware of social comparisons, for example, Denise discusses her sister's family where both parents have a well paid job and 'money is no object at all.' When faced with such comparisons, it is perhaps unsurprising that when asked to some up their lifestyle, only one word comes to Barry's mind: dire.

Both problem and emotional coping strategies are used by respondents. Many problemfocused coping strategies coincide with what Kempson et al. (1994) refer to as managing the family budget, including price comparisons, turning to the alternative sector (both the secondhand market and alternative financial sector), shopping in discount stores and searching for bargains. Some respondents are forced to sell possessions to raise resources and some turn to illicit income and alcohol consumption. Not all strategies are used by all respondents, rather, consumers act in ways that they perceive to be the most fitting for their circumstances. For example, some families benefit from social support from extended family members and other families cope alone; in some families children help with the coping process and in other families they are a hindrance to it; in some families, the pressures of poverty improve 
interpersonal relationships while in other families, extra strain on family members leads to conflict. In terms of emotional coping strategies, while the majority of informants have internalized the ideologies of the consumer society (for example, the desire for material possessions), others are able to disengage and resist pressures to conform to perceptions of socially acceptable consumption behaviour. Rather, these consumers engage in what is 'normal' behaviour for them. For example, some imply that it is 'normal' to live a value and budget conscious lifestyle, suggesting that it is those who overspend who are acting irrationally. In this way findings highlight the diversity of the low-income consumer population.

\section{Paradoxes of Coping with Poverty}

The following sections will focus on the paradoxical nature of coping with poverty and demonstrate that strategies aimed at masking poverty and avoiding stigma may have unintended consequences. Each section will present the informants' voices and then discuss their perspectives with reference to recent exclusion discourse in the UK on 'chav' culture (alongside regional variations in semantics). Often believed to stand for 'Council Housed and Violent,' popular media representations and discourse surrounding chav culture is overwhelmingly negative. The chav 'represents a popular reconfiguration of the underclass idea' (Hayward \& Yar, 2006, p. 10) that 'has made class differences and antagonisms explicitly visible in contemporary Britain' (Tyler, 2008, p. 20). Murray (1990) focused on unemployment, crime and illegitimacy as indicators of the underclass. Reflective of the societal shift from a work ethic to a consumption ethic (Bauman, 2005) chav discourse adds consumption practices to this list (Hayward and Yar, 2006). 


\section{Stigma Avoidance and Keeping Up Appearances}

A key driver of the coping strategies employed by low-income consumers is the avoidance of stigmatization and alleviation of threats to social identity. As well as dealing with material hardships, respondents have to cope with negative attitudes and reactions from others. For example, Janice, a 23 year-old single mother with two children, believes that she is deemed as inferior due to her limited financial resources:

'I know people do judge you, there are people who look down on you for what you wear and the way you talk, there are people who will look down on you for any reason. My friends back home all have jobs and houses and cars. My mum has a big house, my brother who is four years younger than me has his own house and car, and I feel like I'm stuck on the outside.'

Projections of negativity from others, both real and perceived, impact on low-income consumers' self-image and consequently self-definition is influenced by perceived social definition, leading to feelings of shame if they feel they are falling short of what they really ought to be (Goffman, 1963). To cope with these feelings of inadequacy, some informants engage in downward social comparison:

Louise: 'One day we were walking out there and she [5 year-old daughter] said to me, "Mummy aren't we poor" and I was trying to explain to her that there are other children in different countries who are poor, trying to tell her what poor is, trying to tell her that we're very lucky to have what we have so she's not too bad at all.'

Catherine: 'If you get involved with other groups and other people who are all in the same position as you, you think my story is not half as bad as their story and you think what am I so down for?' 
Similar to the distancing strategy identified by Hill \& Stamey (1990), comparing oneself with people in more severe financial difficulties reduces informants' feelings of dissatisfaction with their own situations.

Perceptions of stigmatisation not only lead to emotional effects but incite particular consumption practices. As was evident in the vignettes above, stigma avoidance strategies are often directed at the protection of children, something that the mothers in this study take very seriously. To illustrate, Amy places great emphasis on being a good mother to her 2 year old son, "now that the baby is starting to grow I wonder am I going to be able to afford everything that he wants? Am I going to be a good enough mother?' Amy comes from a troubled background and spent time 'in care' and makes great efforts to ensure that her son's childhood is better than her own. When asked about hopes for the future, Amy's reply is centered on providing for her son:

'you have to understand that for a lot of my life I was going through a shitty time and I didn't want to live so I just take it day by day and don't try and see too far into the future. What I do want is that me and my baby are comfortable and he has all the things that he needs, even clothes, water, heating and I'd be happy with that.'

For the respondents, good motherhood means placing the needs of their children before their own and ensuring children have the material resources necessary to 'fit in' with their peers. For many, especially those with school age children, this involves the purchase of brand name clothing:

Eva: 'she's at that age now where I think it's going to be really difficult and she needs new clothes every couple of months because she seems to be getting bigger and stretching. She knows all the brand names but only through her friends. Now that everybody is going back to school after the summer holidays I couldn't get her ordinary 
shoes, it had to be Nike Air Max but that's because she's going to big school. If it had been at primary you could have got away with it but at 12 you couldn't.'

Interviewer: 'do you think peer pressure has a big influence on children?'

Eva: 'Kids are always in the town now, you don't see kids out playing any more, every Saturday, they're all in the town. Always buying, different hair bobbles, different bangles, everything, they just seem to be buying non-stop. And it's just rubbish, just for the sake of going into town. Personally, I would just go round a few shops. I wouldn't do all the shops, that would do my head in, it would depress me. I don't have enough money, if you've money you can do anything. And then there's the catalogue.'

Interviewer: 'do you shop in catalogues?'

Eva: 'I do because you're paying it off, There's times I just couldn't go to the town and spend $£ 30$ or $£ 40$, I mean some of these Reeboks and all that Erin would want, I mean I couldn’t take $£ 35$ out of my money, I can’t do it. And my credit union, I pay it too. I get it for Christmas and then I have it down and you can hit them again at Christmas, for the things that you can't get in the catalogues, like a bit of jewellery or something that isn't there. I'd be afraid of credit cards, I stick to my credit union and my catalogue because I can manage it better. You see if you don't, I've known people who have gotten into a lot of difficulty. It's just trying to keep up with everyone else, trying to keep the kids up with the other kids.'

Coping through consumption is one of the most utilised coping strategies and consistent with the 'commodification' of youth culture (Klein 2005, p. 65) there is emphasis placed on ensuring children have access to the 'right' brands. Brands assume an important role in young people's everyday lives to facilitate identity construction (Archer, Hollingworth \& Halsall, 2007). Throughout the interviews, children often displayed and discussed different items of 
branded clothing and footwear that they owned, for example, Sarah's 15 year old son proudly showed off his new Nike trainers while Lorna (aged 12) showed her Diesel jeans. Indeed, as evidenced in the interview extract above and the vignettes, parents claim to be powerless in preventing their children from wanting brands, for example Eva commented "I couldn't get her ordinary shoes, it had to be Nike Air Max" and Barry suggested "you have to let them have it." By adopting a variety of persuasion and influence strategies, children become empowered in family consumption decisions while parents take a more passive role. Several contemporaneous studies in both high and low income families reveal similar findings in relation to the prioritisation of children's needs and wants to ensure peer inclusion (Power, 2005; Kochuyt 2004, Evans and Chandler, 2006). As a result, this demands careful negotiation of the household budget and at times, can encourage the use of various forms of credit.

While low-income consumers may regard conspicuous consumption as an effective means of masking poverty, a turn to published material on chav culture suggests otherwise. Chav discourse is best considered in relation to excessive consumption (Hayward \& Yar, 2006). As Tyler $(2008$, p. 21) claimed, the chav 'is primarily identified by means of his or her "bad," "vulgar" and excessive consumer choices - cheap brands of cigarettes, cheap jewellery, branded sports tops, gold-hooped earrings, sovereign-rings, Burberry baseball caps.' Paradoxically, the very consumption practices that provoke stigma are those which are strongly coveted by low-income consumers:

Melissa: 'I see others who have Reebok and Nike and Caterpillar boots and jewellery dripping off them and I just think how do I reach that?'

A return to the vignettes reinforces this idea with examples of Sarah acquiring gold jewellery and Denise and Barry purchasing the branded sports tops worn by their teenage sons. For 
informants, the purchase and display of brand names is viewed as a way of avoiding stigma and could be considered as a disconfirmation of the stereotype (Miller \& Major, 2000). Given that consumption can be viewed as a process of classification that creates social boundaries and reflects social stratification (Baudrillard, 1998; Bourdieu 1984), such strategies are aimed at disguising restricted class positions. According to Bourdieu (1984, p. 56) the 'refusal of tastes' plays a key role in consumer choice as people avoid the purchase of goods and services that may be detrimental to their social self-concept. Within the current context, this includes the rejection of low-cost clothing and other items that may suggest poverty. However, some of the brand names that these consumers purchase to escape stigmatization are the same brands that have particular negative user stereotypes associated with them. Brand images of exclusivity and respectability have been undermined (Nayak 2006, p. 820) and no longer communicate intended identity messages. In a cruel irony, the consumption choices that are driven by a desire to mask poverty instead only serve to further stigmatise.

\section{Empowerment and single motherhood}

Evidence suggests that coping efforts may be empowering for single mothers and can result in higher self-esteem if they feel that they can cope with the demands of their family in relation to consumer society. Indeed, there is a strong emphasis on remaining independent: Louise: 'Coming up to buying the school uniform there, it costs about $£ 70$ because you need two of everything because you can't get it in January because all the stock is gone so you have to make sure you buy enough to do her through the year. I phoned up to ask could I apply for a budgeting loan, it was only for $£ 60$ and I explained what it was for and the girl said that should be no problem, you haven't got a big debt here or anything and then they sent me a letter saying that I couldn't have it. That was a Saturday morning, I 
had woken up really really happy and by the end of the day I couldn't stop crying, I just couldn't stop crying. I thought this is awful crying about money but then I thought it doesn't matter, it's going to be ok, you're been through worse and somebody's always helped you out. I have a big family and I've good friends who would all be very cross to think that I'd been lying there crying about money when they could help.'

Others concurred that seeking social support from others is a last resort. Such reluctance to ask for help may be explained by the sense of achievement gained from coping with difficult circumstances. Many respondents are proud of their ability to 'manage' and remaining independent can have a positive impact on self-identity, especially for single mothers:

Amy: 'I'm a very independent person, I've been living on my own since I've been 16 so anything I've ever done, it has all been put up by me or put together by me. I would never have anybody turn around and say that I owe them anything.'

Clare: 'I'm raising him on my own and I work to support him and I support myself at university as well. I try to balance things out, it is quite balanced, I have time to work, I have time to be a Mummy and study at the same time.'

Julie: 'I've had to really work for what I've got and at times get into hard amounts of debt and a lot of stuff that I have got is all through me, no-one else. My parents aren't supportive at all. I've had to save for everything that I've got so I appreciate money a lot more... sometimes I would go to bed and just think, oh my God, how did you get through all that, it amazes me how I can find the money to pay for some of the bills that I have.'

Many of the respondents who placed emphasis on independence were in their early 20 s and relatively young mothers themselves. This was a great source of self-esteem, especially in societies that often condemn the irresponsibility of early single motherhood. This 
interpretation of empowerment provides an optimistic image of coping within the challenging context of consumer culture to improve the standard of living for themselves and their family. They enjoy feelings of independence, defined for them as managing without the help of their children's father, their parents or other family support. Similar to the young mothers involved in MacDonald and Marsh's (2005, p. 150) study, respondents are 'emotionally and morally committed to mothering.'

However, one need only consider Tyler's (2008) article 'Chav Mum Chav Scum' to understand that the stigmatisation of single motherhood is just as prevalent today as at the time of Murray's (1990) thesis. This leads to the emergence of another paradox. At a micro level, perceived success at coping helps to build self-esteem for single mothers. However, if we move beyond the level of lived experience to consider wider social discourse, alternative understandings emerge. Welfare policy in most developed countries advocates that single mothers should provide at least some of their own income. In this context, reliance on welfare benefits may indicate dependency, not the independence that these mothers believe to have achieved. Within such discourse, the welfare mother is stigmatized as non-productive by living on benefits, and also a bad mother who is harming the life chances of her children (Wilson \& Huntington, 2006). This emphasis on paid work and employment excludes the unpaid work that all single mothers perform (Christopher, 2004).

\section{IMPLICATIONS}

Negative social representations, particularly as portrayed through the media, lead to the reproduction of meanings that position low-income consumers as separate and abnormal (Tyler, 2008). In this way, poverty becomes a social construction and judgments about the 
moral and material positions of low-income consumers abound. Through the media we witness the 'labeling, stereotyping, separation, status loss, and discrimination' (Link \& Phelan, 2001, p. 367) of poor consumers. This is similar to Murray's (1990) focus on the deviant behavioural norms that define the underclass as a moral category. It is precisely this tendency to view single mothers as a homogeneous group that results in stereotypes and stigmatisation. The conflation of all single mother households facilitates the social construction of single motherhood as a social problem (Kanji, 2004). Such generalisation overlooks the heterogeneity of low-income families. Many make significant efforts to exercise agency. Similar to Blackman's (1997) study on young homeless people, they employ coping strategies that create a culture of survival. They are far removed from those who are 'lazy, criminal and responsible for their circumstances' (Becker, 1997, p.1) and bear little similarity to the 'charvers,' depicted in Nayak's (2006) study. Equally, similar to Williamson's (1997), study of Status Zer0 young people, many were propelled into their situation by factors outside their control. This suggests that there is a need to look beyond indicators such as clothing or employment status, and instead, listen to the voices of stigmatized individuals themselves.

Despite the significant efforts made by some low-income consumers, it appears that coping strategies to avoid stigma do not always work. It is important to consider the role of marketing in this paradox. Through images of material wealth, marketing promotes a lifestyle of plenty and abundance. Indeed much of which we are presented with through marketing communications drives our desire for excess as we are encouraged to strive for the newest technology, the latest designer handbag, and the most expensive car. Perhaps this is most evident within the youth market as marketers drive 'the quest for cool' (Klein, 2005, p. 69). Marketing techniques that increase competitive consumption and social comparisons 
(Festinger, 1954) contribute to the shame of excluded consumers (Bowring, 2000). It is ironic that low-income consumers are excluded for aspiring towards the lifestyle that marketers have been presenting us with for years. The source of their stigmatization stems from their desire to share in material conditions that are part and parcel of the consumer culture. This implies that in order to completely understand the consequences of marketing activities, they need to be considered in a broader context, exploring not only their managerial implications but societal implications as well.

\section{CONCLUSION}

While previous research has identified the coping strategies employed by low-income consumers (Hill \& Stephens, 1997; Kempson et al. 1994), this study contributes by identifying the effects of such strategies. The findings reveal that low-income consumers place emphasis on conspicuous consumption to avoid the social effects of stigmatisation and that the employment of coping strategies can have a positive impact on the self-esteem of single mothers. Further, this paper compares the lived experience of poverty with wider social discourse on chav culture and single mothers. This is important as stigma is both a psychological and a social process (Campbell \& Deacon, 2006). This approach reveals the paradoxical nature of consumption in poverty. If the coping strategies of low-income consumers are interpreted in relation to sociocultural understandings, it becomes apparent that those who follow a strategy of conspicuous consumption to mask poverty encounter the very stigmatization that they set out to avoid in the first instance.

Adherents of Murray's (1990) underclass thesis may be encouraged to associate the unemployed and single parents in this study with deviant behaviour that threatens social and 
moral standards. By highlighting the lived experience of families in poverty this research has demonstrated that taking Murray's (1990) indicators at face value may lead to potentially dangerous misconceptions. Similar to Blackman's (1997) work on young homeless people, the informants in this study do not reject societal values. Indeed, by attempting to contest and resist the stigmatizing regime, low-income consumers seek consumer normalcy (Baker, 2006) through their marketplace transactions.

It is only by developing policy approaches that acknowledge diversity amongst the low income population that we can hope to overcome the stigmatisation of the poor as a social threat. The incompatibility of Government policy and a diverse population gains greater significance given the grip of consumer culture. As Bauman $(1998,59)$ articulated, "If the marketing of products cannot operate without promoting (through lip service at least) the cult of difference and choice, the idea of the welfare state makes little sense without appealing to the idea of the sameness of the human condition, human needs and human rights." The reconciliation of these competing discourses remains highly problematic.

There are a number of limitations to the study which represent opportunities for future research. Only one interview was held in each family. Given the dynamic nature of poverty, future research that adopts a longitudinal approach would provide a welcome contribution by demonstrating how each family's situation changes over time. Alwitt and Donley (1996) developed a marketing exchange model for low-income consumers, suggesting that marketers, the Government, the rest of society and social services are all parties to exchange relationships for low-income consumers. This study has considered only the perspective of low-income consumers. Future research could offer multiple perspectives by encompassing these other parties. Children under the age of 11 were not included in the data collection. 
Future studies that focus exclusively on the ways that poverty affects children could generate important contributions. Finally, this paper has highlighted the way in which consumption practices can serve as an integrating force within society. Future research could further explore the link between consumption and social exclusion. 


\section{REFERENCES}

Alwitt, L. F. \& Donley, T. D. (1996) The Low-Income Consumer: Adjusting the Balance of Exchange. Thousand Oaks, CA: Sage.

Archer, L.; Hollingworth, S. \& Halsall, A. (2007) 'University’s not for me - I'm a Nike person': Urban, Working Class Young People's Negotiations of 'Style', Identity and Educational Engagement', Sociology, 41 (2): 219-237.

Baker, S. M. (2006) 'Consumer normalcy: Understanding the value of shopping through narratives of consumers with visual impairments', Journal of Retailing, 82 (1): 37-50.

Baudrillard, J. (1998) The Consumer Society. London: Sage.

Bauman, Z. (2005) Work, Consumerism and the New Poor. Buckingham: Open University Press.

Becker, S. (1997) Responding to Poverty: The Politics of Cash and Care. London: Longman. Blackman, S. J. (1997) “'Destructing a Giro': A Critical and Ethnographic Study of the Youth 'Underclass'. In R. MacDonald (Ed.) Youth, the 'Underclass' and Social Exclusion (pp. 113-129). London: Routledge.

Bourdieu, P. (1984) Distinction: A Social Critique of the Judgement of Taste. London: Routledge.

Bowring, F. (2000) 'Social Exclusion: Limitations of the Debate', Critical Social Policy, 20 (3): $307-330$.

Breakwell, G. M. (1986) Coping With Threatened Identities. London: Methuen.

Campbell, C \& Deacon, H. (2006) 'Unravelling the Contexts of Stigma: From Internalisation to Resistance to Change', Journal of Community \& Applied Social Psychology, 16: 411-417.

Caplovitz, D. (1967) The Poor Pay More, Consumer Practices of Low-Income Families. New York: The Free Press. 
Carver, C.S., Scheier, M. F. \& Weintraub, J. K. (1989) 'Assessing Coping Strategies: A Theoretically Based Approach', Journal of Personality and Social Psychology, 56 (2): 267-283.

Christopher, K. (2004) 'Welfare As We [Don't] Know It: A Review and Feminist Critique of Welfare Reform Research in the United States', Feminist Economics, 10 (2): 143-171. Curtis, J. (2000) 'Low Income, Low Priority', Marketing, Oct. $26^{\text {th }}, 36-37$.

Darley, W. K. \& Johnson, D. M. (1985) 'A Contemporary Analysis of the Low Income Consumer: An International Perspective'. In C. T. Tan and J. N. Sheth (Eds.), Historical Perspectives in Consumer Research: National and International Perspectives (pp. 206-210). Provo, UT: Association for Consumer Research.

Evans, J. \& Chandler, J. (2006) 'To Buy or not to Buy: Family Dynamics and Children's $\begin{array}{lllll}\text { Consumption', } & \text { Sociological } & \text { Research } & \text { Online, } & 11\end{array}$ http://www.socresonline.org.uk/11/2/evans.html.

Featherstone, M. (1990) 'Perspectives on Consumer Culture', Sociology, 24 (1): 5-22.

Festinger, L. (1954) 'A Theory of Social Comparison Processes', Human Relations, 7: 117140.

Folkman, S., Lazarus, R. S., Dunkel-Schetter, C., DeLongis, A., \& Gruen, R. J. (1986) 'Dynamics of a Stressful Encounter: Cognitive Appraisal, Coping, and Encounter Outcomes', Journal of Personality and Social Psychology, 50 (5): 992-1003.

Franklin, C. (1996) 'Learning to Teach Qualitative Research: Reflections of a Quantitative Researcher', Marriage and Family Review, 24 (3/4): 241-274.

Goffman, E. (1963) Stigma: Notes on the Management of Spoiled Identity. London: Penguin Books. 
Gordon, D., Adelman, L., Ashworth, K., Bradshaw, J., Levitas, R., Middleton, S., Pantazis, C., Patsios, D., Payne, S., Townsend, P. \& Williams, J. (2000) Poverty and Social Exclusion in Britain. York: Joseph Rowntree Foundation.

Hamilton, K. \& Catterall, M. (2006) 'Consuming Love in Poor Families: Children's Influence on Consumption Decisions', Journal of Marketing Management, 22 (9): $1025-2046$.

Hamilton, K. (2009) 'Low-Income Families: Experiences and Responses to Consumer Exclusion', International Journal of Sociology and Social Policy, 29 (9/10): 543-557.

Hayward, K. \& Yar, M. (2006) 'The 'chav' phenomenon: Consumption, media and the construction of a new underclass', Crime Media Culture, 2 (1): 9-28.

Hill, R. P. (1991) 'Homeless Women, Special Possessions, and the Meaning of "Home": An Ethnographic Case Study', Journal of Consumer Research, 18: 298-310.

Hill, R. P. \& Stamey, M. (1990) 'The Homeless in America: An Examination of Possessions and Consumption Behaviors', Journal of Consumer Research, 17: 303-321.

Hill, R. P. \& Stephens, D. L. (1997) 'Impoverished Consumers and Consumer Behavior: The Case of AFDC Mothers', Journal of Macromarketing, 17 (2): 32-48.

Isaken, K. J. \& Roper, S. (2008) 'The Impact of Branding on Low-income Adolescents: A Vicious Cycle?' Psychology and Marketing, 25 (11): 1063-1087.

Joseph Rowntree Foundation (2009) Monitoring poverty and social exclusion 2009. York: Joseph Rowntree Foundation.

Kanji, S. (2004), 'The Route Matters: Poverty and Inequality Among Lone-Mother Households in Russia’, Feminist Economics, 10 (2): 207-225.

Kempson, E., Bryson, A. \& Rowlingson, K. (1994) Hard Times? How Poor Families Make Ends Meet. London: Policy Studies Institute.

Klein, N. (2005) No Logo. London: Harper Perennial. 
Kochuyt, T. (2004) 'Giving Away One’s Poverty. On the Consumption of Scarce Resources within the Family', The Sociological Review, 52 (2): 139-161.

Lazarus, R. S. \& Folkman, S. (1984) Stress, Appraisal and Coping. New York: Springer Publishing Company.

Lewis, O. (1965) La Vida: A Puerto Rican Family in the Culture of Poverty - San Juan and New York. London: Secker and Warburg.

Link, B. G. \& Phelan, J. C. (2001) 'Conceptualising Stigma', Annual Review of Sociology, 27: $363-85$.

MacDonald, R. \& Marsh, J. (2005) Disconnected Youth? Growing Up in Britain's Poor Neighbourhoods. Basingstoke: Palgrave.

Miller, D. (1998) A Theory of Shopping. Cambridge: Polity Press.

Miller, C. T. \& Major, B. (2000) 'Coping with Stigma and Prejudice'. In T. F. Heatherton, R. E. Kleck, M. R. Hebl \& J. G. Hull (Eds.) The Social Psychology of Stigma (pp. 243272). New York: The Guilford Press.

Murray, C. (1990) The Emerging British Underclass. London: Institute of Economic Affairs.

Nayak, A. (2006) 'Displaced Masculinities: Chavs, Youth and Class in the Post-industrial City', Sociology, 40 (5): 813-831.

Patton, M. Q. (2002) Qualitative Research and Evaluation Methods. Thousand Oaks, CA: Sage.

Power, E. (2005) 'The Unfreedom of Being Other: Canadian Lonemothers' Experiences of Poverty and Life 'on the cheque', Sociology, 39 (4), 643-66.

Thompson, C. J., Pollio, H. R. \& Locander, W. B. (1994) 'The Spoken and the Unspoken: A Hermeneutic Approach to Understanding the Cultural Viewpoints that Underlie Consumers' Expressed Meanings', Journal of Consumer Research, 21 (3): 432-452. 
Tyler, I. (2008) 'CChav Mum Chav Scum' Class Disgust in contemporary Britain', Feminist Media Studies', 8 (1): 17-34.

Williams, C. C. \& Windebank, J. (2001) 'Acquiring Goods and Services in Lower Income Populations: An Evaluation of Consumer Behaviour and Preferences', International Journal of Retail and Distribution Management, 29 (1): 16-24.

Williamson, H. (1997) 'Status Zer0 Youth and the 'Underclass': Some considerations'. In R. MacDonald (Ed.) Youth, the 'Underclass' and Social Exclusion (pp. 70-82). London: Routledge.

Wilson, H. \& Huntington, A. (2006) 'Deviant (M)others: The Construction of Teenage Motherhood in Contemporary Discourse', Journal of Social Policy, 35 (1): 59-76. 
Table 1: Profile of Respondent Details

\begin{tabular}{|c|c|c|c|c|}
\hline Pseudonym (age) & Interview Type & $\begin{array}{l}\text { Weekly } \\
\text { Income }\end{array}$ & Family Details & Employment \\
\hline $\begin{array}{l}\text { Sarah (46), Martin (15), } \\
\text { Ella (13), Linda (11) }\end{array}$ & $\begin{array}{l}\text { Mother, } 1 \text { son, } 2 \\
\text { daughters }\end{array}$ & $£ 160$ & $\begin{array}{l}\text { Lone parent, } 6 \text { children } \\
\text { (4 under 18) }\end{array}$ & unemployed \\
\hline $\begin{array}{l}\text { Brenda (32), Ann (14), } \\
\text { Lorna (12), Gareth (11) }\end{array}$ & $\begin{array}{l}\text { Mother, } 2 \\
\text { daughters, } 1 \text { son }\end{array}$ & $£ 169$ & Lone parent, 2 children & unemployed \\
\hline Philip (48), Joanne (16) & $\begin{array}{ll}\begin{array}{l}\text { Father } \\
\text { daughter }\end{array} & \text { and } \\
\end{array}$ & $£ 82$ & Lone parent, 1 child & unemployed \\
\hline Zoe (43), Jenny (16) & $\begin{array}{l}\text { Mother and } \\
\text { daughter }\end{array}$ & $£ 99$ & Lone parent, 2 children & unemployed \\
\hline Donna (39), Paul (15) & Mother and son & $£ 99$ & Lone parent, 1 child & unemployed \\
\hline Janet (38), Pamela (16) & $\begin{array}{l}\text { Mother and } \\
\text { daughter }\end{array}$ & $£ 198$ & Lone parent, 3 children & unemployed \\
\hline Maria (38), Ryan (17) & Mother and son & $£ 160$ & Lone parent, 3 children & unemployed \\
\hline Lorraine (43), Lisa (14) & $\begin{array}{l}\text { Mother and } \\
\text { daughter }\end{array}$ & $£ 107.50$ & Lone parent, 3 children & unemployed \\
\hline $\begin{array}{l}\text { Catherine (40), Samantha } \\
\text { (15) }\end{array}$ & $\begin{array}{l}\text { Mother and } \\
\text { daughter }\end{array}$ & $£ 146$ & Lone parent, 3 children & unemployed \\
\hline Rebecca (23), James (30) & Couple & $£ 185$ & 2 parent, 2 children & unemployed \\
\hline Fiona (25), Jason (28) & Couple & $£ 190$ & 2 parent, 2 children & Both unemployed \\
\hline Erin (29) and John (30) & Couple & $£ 200$ & 2 parent, 2 children & $\begin{array}{l}\text { John - chef } \\
\text { Erin - unemployed }\end{array}$ \\
\hline Jodie (42), Daniel (43) & Couple & $£ 170$ & 2 parent, 2 children & Both unemployed \\
\hline Denise (43), Barry (40) & Couple & $£ 190$ & 2 parent, 2 children & Both unemployed \\
\hline Jessica (38) & Individual & $£ 200$ & Lone parent, 2 children & Women's centre manager \\
\hline Hannah (25) & Individual & $£ 148$ & Lone parent, 3 children & unemployed \\
\hline Susan (23) & Individual & $£ 170$ & Lone parent, 2 children & Part time waitress \\
\hline Emma (36) & Individual & $\begin{array}{l}£ 190- \\
£ 200\end{array}$ & Lone parent, 2 children & $\begin{array}{l}\text { Part time pharmacy } \\
\text { assistant }\end{array}$ \\
\hline Amanda (36) & Individual & $£ 135.30$ & Lone parent, 2 children & Unemployed \\
\hline Clare (25) & Individual & $£ 250$ & Lone parent, 1 child & $\begin{array}{l}\text { Part time youth worker, } \\
\text { part time student }\end{array}$ \\
\hline Tammy (27) & Individual & $£ 140$ & Lone parent, 2 children & unemployed \\
\hline Melissa (31) & Individual & $£ 206$ & Lone parent, 5 children & unemployed \\
\hline Eva (45) & Individual & $£ 110.50$ & Lone parent, 3 children & unemployed \\
\hline Louise (25) & Individual & $£ 100$ & Lone parent, 1 child & unemployed \\
\hline Amy (23) & Individual & $£ 180$ & Lone parent, 1 child & $\begin{array}{l}\text { Unemployed/ voluntary } \\
\text { work }\end{array}$ \\
\hline Julie (24) & Individual & $£ 144$ & Lone parent, 1 child & full time student \\
\hline Jackie (23) & Individual & $£ 110$ & Lone parent, 1 child & unemployed \\
\hline Nina (23) & Individual & $£ 140$ & Lone parent, 1 child & $\begin{array}{l}\text { Full time student, part- } \\
\text { time bar work }\end{array}$ \\
\hline Janice (23) & Individual & $£ 110$ & Lone parent, 2 children & unemployed \\
\hline Gemma (19) & Individual & $£ 100$ & Lone parent, 1 child & unemployed \\
\hline
\end{tabular}

